\title{
Continuous Flow Photo-Oxidations using Supported Photocatalysts on Silica
}

Vincent Blanchard, ${ }^{\ddagger}$ Zakariae Asbai, ${ }^{\dagger}$ Kevin Cottet, ${ }^{\ddagger}$ Guillaume Boissonnat, ${ }^{\ddagger}$ Marc Port, ${ }^{\dagger}$ Zacharias Amara ${ }^{* \dagger}$

$\dagger$ Equipe Chimie Moléculaire, Laboratoire de Génomique, Bioinformatique et Chimie Moléculaire, (GBCM), EA 7528, Conservatoire national des arts et métiers, HESAM Université, 2 rue Conté, 75003, Paris Cedex 03, France.

† PILI, 3 rue Ariane, 31520 Ramonville, France

Corresponding author: zacharias.amara@lecnam.net

\section{Supporting Information}

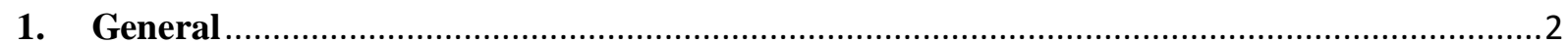

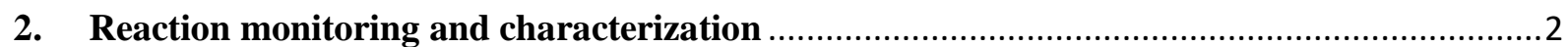

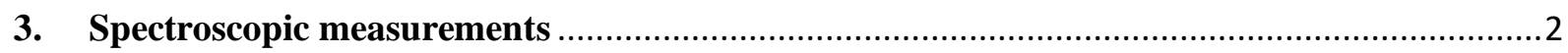

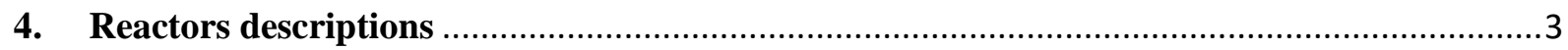

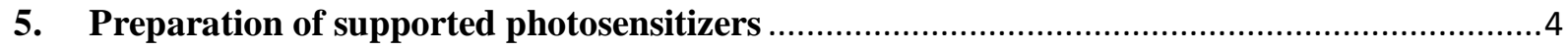



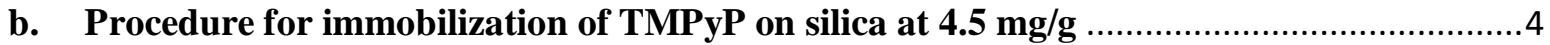

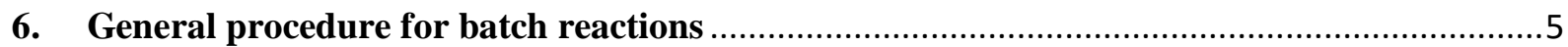

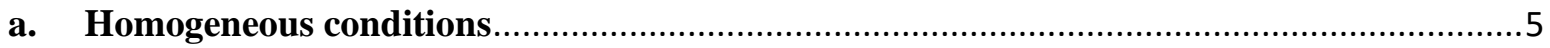

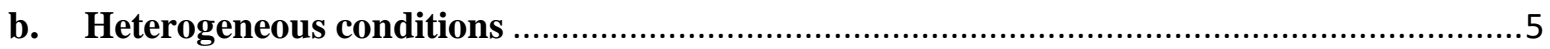

7. General procedure for continuous flow reactions ...........................................................

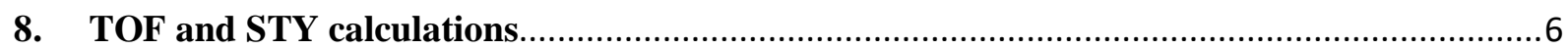

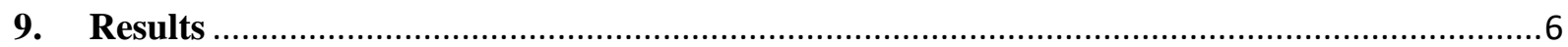

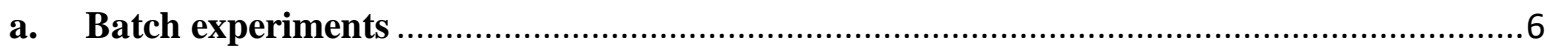



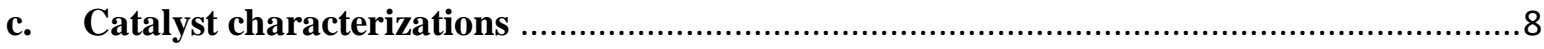

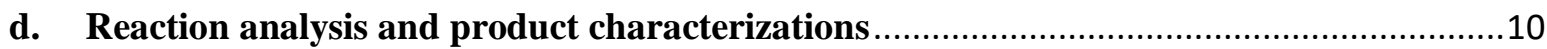




\section{General}

Reagents and solvents were used as received, without further purification, unless otherwise noted. Oxygen (>99.5\%) was obtained from Air Liquide and used as received. Photosensitizers (>98\%) and 1,5-dihydroxynaphtalene (>98\%, stored under argon and in obscurity) were purchased from TCI Chemicals. Silica (60M, 0.04-0.063 mm for column chromatography) was purchased from Macherey-Nagel. Acetonitrile (ACS reagent grade) was purchased from Carlo Erba and used without further purification.

Photochemical experiments were carried out using a bank of Inspire LEDs (4000 K):

-for batch reactor 680 Lumens/m, 6.7 W, LED bands from Inspire arranged in 8 rows around the transparent glass vessel, meaning a total of 5100 Lumens,

-for continuous flow process: 400 Lumens/m, 26 W LED bands from Inspire arranged in 3 rows around the cartridges and 8 rows within the circle made by the arrangement of multiple cartridges, meaning a total of 2500 Lumens.

N.B.: The two LED irradiation systems (2500 lm or $5100 \mathrm{~lm})$ were tested in batch and gave very comparable results.

\section{Reaction monitoring and characterization}

Reactions were monitored by GC-MS analysis on a Shimadzu GC-2010 Plus equipped with a Rxi ${ }^{\circledR}-1 \mathrm{~ms}$ column capillary (12 m x $\left.0.2 \mathrm{~mm}, 0.33 \mu \mathrm{m} \mathrm{df}\right)$ linked to a quadripole mass spectrometer QP2010 SE (start at $50{ }^{\circ} \mathrm{C}$, ramp to $280{ }^{\circ} \mathrm{C}$ at $20{ }^{\circ} \mathrm{C} / \mathrm{min}$ ). Aliquots were taken from the reaction medium and diluted with ethyl acetate before analysis. ${ }^{1} \mathrm{H}$ NMR spectra were recorded on a $400 \mathrm{MHz}$ Bruker Advance Spectrometer in $\mathrm{CD}_{3} \mathrm{CN}(\delta=1.94 \mathrm{ppm})$ or $\mathrm{CDCl}_{3}$ (7.26 ppm). ${ }^{1} \mathrm{H}$ NMR analysis was used to confirm GC-MS conversion results.

\section{Spectroscopic measurements}

UV-Visible spectra were obtained with a Shimadzu UV-2600, equipped with an integration sphere ISR-2600 Plus for powders, scanning using $1 \mathrm{~cm}$ quartz cuvettes (wavelength range $200-800 \mathrm{~nm}$ ). Fluorescent spectra were acquired on a Shimadzu fluorimeter RF6000 using $1 \mathrm{~cm}$ quartz cuvettes (wavelength range $200-800 \mathrm{~nm}$ ). 


\section{Reactors descriptions}

For batch conditions, a jacketed reactor of $200 \mathrm{~mL}$ was used for all our experiments. In the outer jacket, a temperature regulated mixture of water/ethylene glycol (80/20) was circulated to control the reaction temperature. A condenser was used to limit vaporization of solvents and inner temperature was controlled with a thermometer. Oxygen was supplied to the reaction mixture by a balloon. White LED stripes were attached to a PVC tube. The reactor was placed in the centre at a $5 \mathrm{~cm}$ distance from the LEDs as shown in Fig S1.

a)

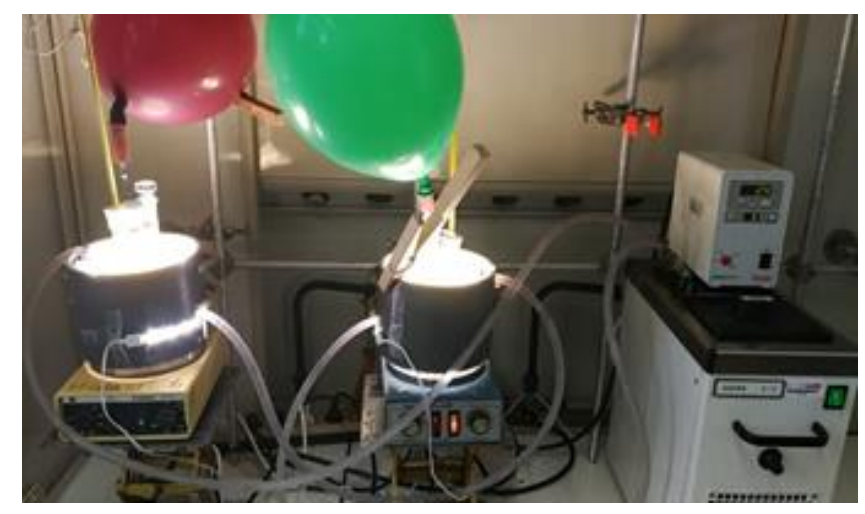

b)

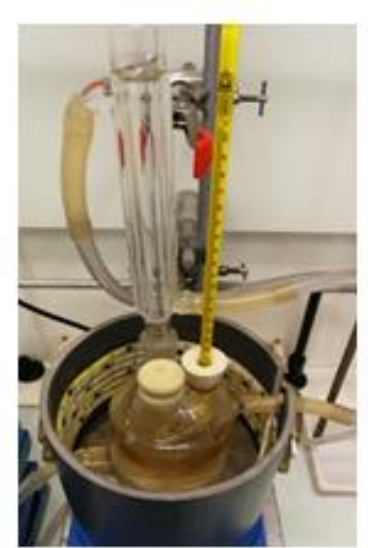

Figure S1: Photographs showing: (a) the thermo-regulated photochemical batch reactors; (b) how the LED lamps are organized around the reactor.

For the continuous flow process, the starting material was pumped as a solution in acetonitrile by a Shimadzu LC-20AT HPLC pump in a 1/16" PTFE tube. Oxygen or air was injected in the 1/16" PTFE tubing system by a computer controlled switching valve (Rheodyne) equipped with a $50 \mu \mathrm{L}$ stainless steel loop. The starting material and the gas were mixed in a T-shape stainless steel union (Swagelok fitting). The reaction mixture was delivered to a $1 / 4$ " PTFE tube containing the silica supported photosensitizer by means of cotton wool to avoid silica leaks. Experiments were carried out by circulating the liquid from the top to the bottom of the reactor. A 1/16" PTFE tube was connected to the end of the tubular reactor. The reaction mixture was then collected in Erlenmeyers. The overall system was ventilated by a fan to keep room temperature around the LEDs. (Fig S2). 


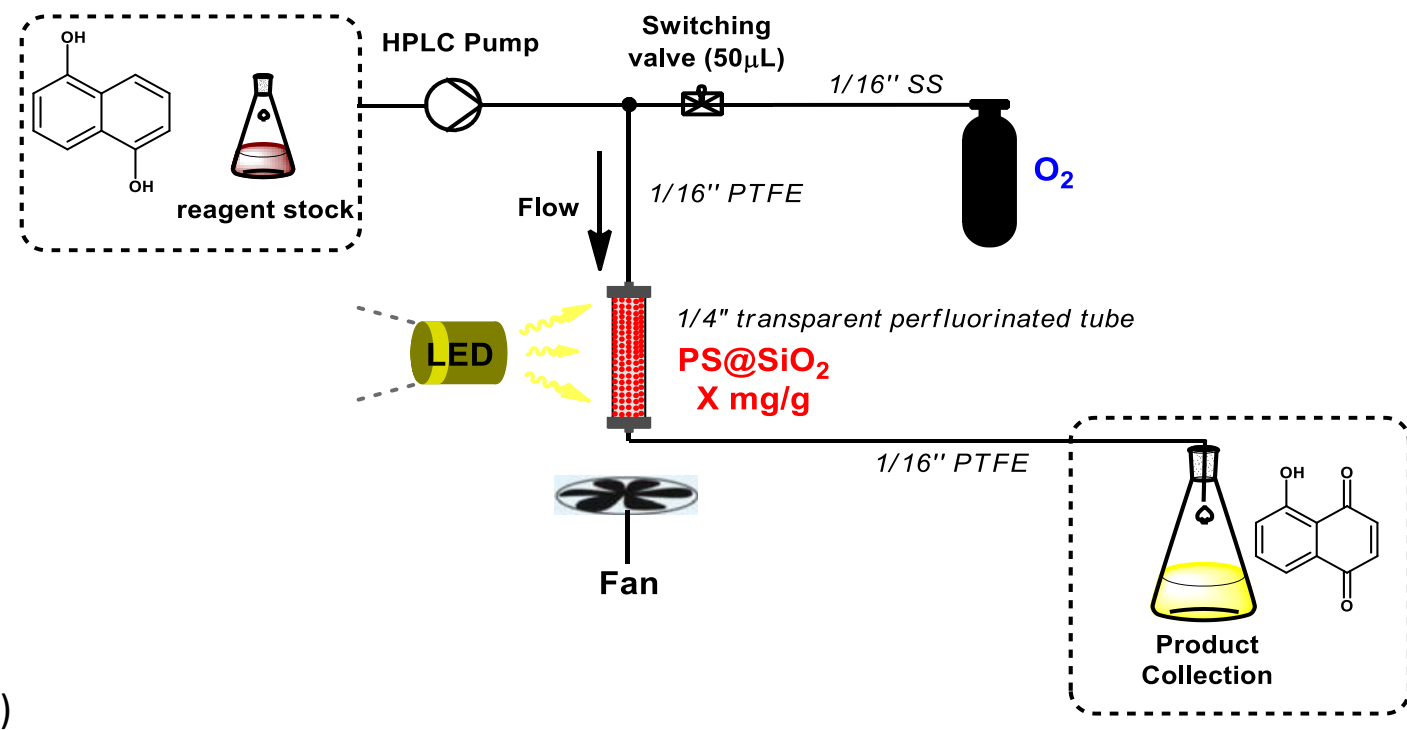

(a)

(b)

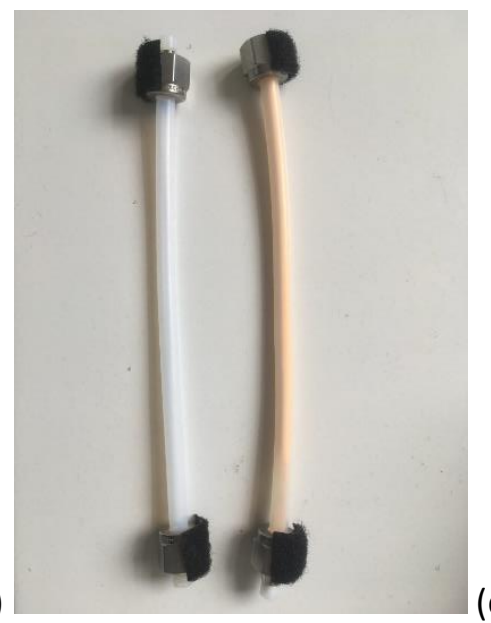

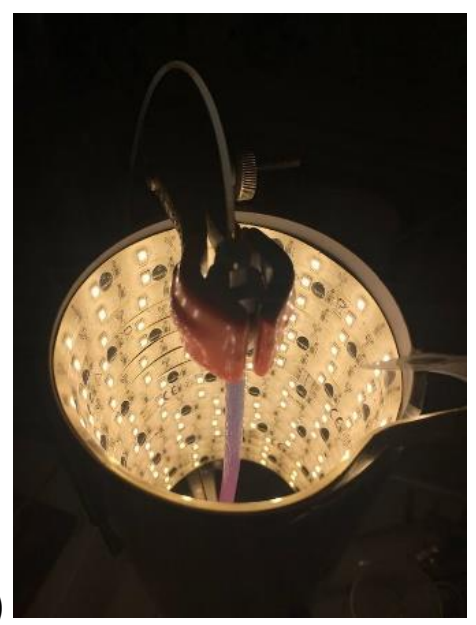

(c)

Figure S2: (a) continuous flow diagram used for the juglone synthesis using a fixed catalytic bed reactor; (b) pictures of the tubular reactor (left: empty, right: filled with $\mathrm{Ru}(\mathrm{bpy})_{3} \mathrm{Cl}_{2} @ \mathrm{SiO}_{2}$ ); (c) picture of the reactor under operating conditions.

\section{Preparation of supported photosensitizers}

\section{a. Procedure for immobilization of $\left[\operatorname{Ru}(\mathrm{bpy})_{3}\right]^{2+}$ on silica at $2.5 \mathrm{mg} / \mathrm{g}$}

A $2.5 \mathrm{~mL}$ ethanol/water $(80 / 20$ ratio $)$ solution of $\mathrm{Ru}(\mathrm{bpy}){ }_{3} \mathrm{Cl}_{2}(1.0 \mathrm{~g} / \mathrm{L})$ was added to a slurry of $1.0 \mathrm{~g}$ of silica in $47.5 \mathrm{~mL}$ of ethanol/water (ratio 80/20) at room temperature. The mixture was stirred for 2 hours at room temperature and then filtered, washed 3 times with $15 \mathrm{~mL}$ of a solution of ethanol/water (ratio 80/20), and the solid was dried in an oven at $80{ }^{\circ} \mathrm{C}$ overnight.

\section{b. Procedure for immobilization of TMPyP on silica at $4.5 \mathrm{mg} / \mathrm{g}$}

TMPyP (45 mg, $33.4 \mu \mathrm{mol})$ was dissolved in $300 \mathrm{~mL}$ of deionised water in a $500 \mathrm{~mL}$

Erlenmeyer. $10.0 \mathrm{~g}$ of silica were added to the solution under magnetic stirring at room 
temperature. After $6 \mathrm{~h}$, the solution was filtered, exhaustively washed 4 times with $40 \mathrm{~mL}$ of water, and the solid was dried in an oven at $80{ }^{\circ} \mathrm{C}$ overnight.

\section{c. Purification}

In case of quantitative conversion to juglone observed by GC-MS for flow process, no purification was necessary to obtain pure juglone after evaporation of the solvent under vacuum.

\section{General procedure for batch reactions}

\section{a. Homogeneous conditions}

A $100 \mathrm{~mL}$ solution of 1,5-DHN (concentration depending of the experiment) was prepared in a given solvent and sonicated for $3 \mathrm{~min}$. Then, $1 \mathrm{~mL}$ from a $10 \mathrm{~mL}$ solution of photosensitizer ( $0.16 \mathrm{~mol} \%$ in relation to $1,5-\mathrm{DHN})$ in the same solvent was added to the solution of 1,5-DHN. The solution was then transferred in the thermo-regulated batch reactor. An oxygen balloon with a needle bubbling in the liquid was used to continuously oxygenate the solution throughout the entire experiment with slow magnetic stirring. The reactor was irradiated by LEDs and the temperature was maintained at $20{ }^{\circ} \mathrm{C}$.

\section{b. Heterogeneous conditions}

A $100 \mathrm{~mL}$ solution of 1,5-DHN (concentration depending of the experiment) in a given solvent was prepared to which supported photosensitizer (quantum satis $0.16 \mathrm{~mol} \%$ equivalent of TMPyP) on silica was added. The slurry was then transferred in the thermo-regulated batch reactor. An oxygen balloon with a needle bubbling in the liquid was used to continuously oxygenate the solution throughout the entire experiment with slow magnetic stirring. The reactor was irradiated by LEDs and the temperature was maintained at $20{ }^{\circ} \mathrm{C}$.

\section{General procedure for continuous flow reactions}

A solution of 1,5-DHN (concentration depending of the experiment) was prepared in $100 \mathrm{~mL}$ of acetonitrile, sonicated for $3 \mathrm{~min}$ and protected from light with an aluminum foil. After this the cartridge was filled with $1.3 \mathrm{~g}$ of supported PS and placed at the center of a tube where LED strips are attached. The 1,5-DHN solution was pumped in the system at a constant flow rate throughout the entire experiment. 


\section{TOF and STY calculations}

Table S1: Calculation of STY and TOF for batch or flow reactions:

\begin{tabular}{ccc}
\hline & Batch & Flow \\
\hline STY $\left(\mathrm{g} . \mathrm{L}^{-1} \cdot \mathrm{h}^{-1}\right)$ & $\frac{[1,5-D H N] \times M(J) \times \eta}{\Delta t \times 100}$ & $\frac{D \times[1,5-D H N] \times \eta \times M(J) \times 0.0006}{V(C)}$ \\
TOF $\left(\mathrm{h}^{-1}\right)$ & $\frac{[1,5-D H N] \times V \times \eta \times M(P S)}{m(P S) \times C(P S) \times \Delta t \times 100}$ & $\frac{0.6 \times D \times[1,5-D H N] \times M(P S) \times \eta}{m(P S) \times C(P S)}$ \\
\hline
\end{tabular}

[1,5-DHN] = starting concentration of 1,5-DHN in mol/L; $\mathrm{M}(\mathrm{J})=$ molecular weight of juglone in $\mathrm{g} / \mathrm{mol} ; \mathrm{M}(\mathrm{PS})=$ molecular weight of photosensitizer in $\mathrm{g} / \mathrm{mol} ; \eta=$ conversion in $\% ; \Delta t=$ reaction duration in hour; $D=$ flow rate of 1,5-DHN in $\mathrm{mL} / \mathrm{min} ; \mathrm{V}(\mathrm{C})=$ reactor volume in $\mathrm{mL}$ when filled with silica; $\mathrm{V}=$ solution volume in batch in $\mathrm{mL}$; $C(P S)=$ amount of photosensitizer adsorbed on silica in $\mathrm{mg} / \mathrm{g} ; \mathrm{m}(\mathrm{PS})=$ quantity of silica used as support.

\section{Results}

\section{a. Batch experiments}

Results obtained with $\mathrm{Ru}(\mathrm{bpy}){ }_{3} \mathrm{Cl}_{2}$ in pure acetonitrile and in a $1 / 1$ mixture of acetonitrile and dichloromethane are presented hereafter with $[1,5-\mathrm{DHN}]=0.01 \mathrm{M}$ and $0.16 \mathrm{~mol} \%$ of $\mathrm{PC}$ at $20^{\circ} \mathrm{C}$ (Fig S3).

(a)

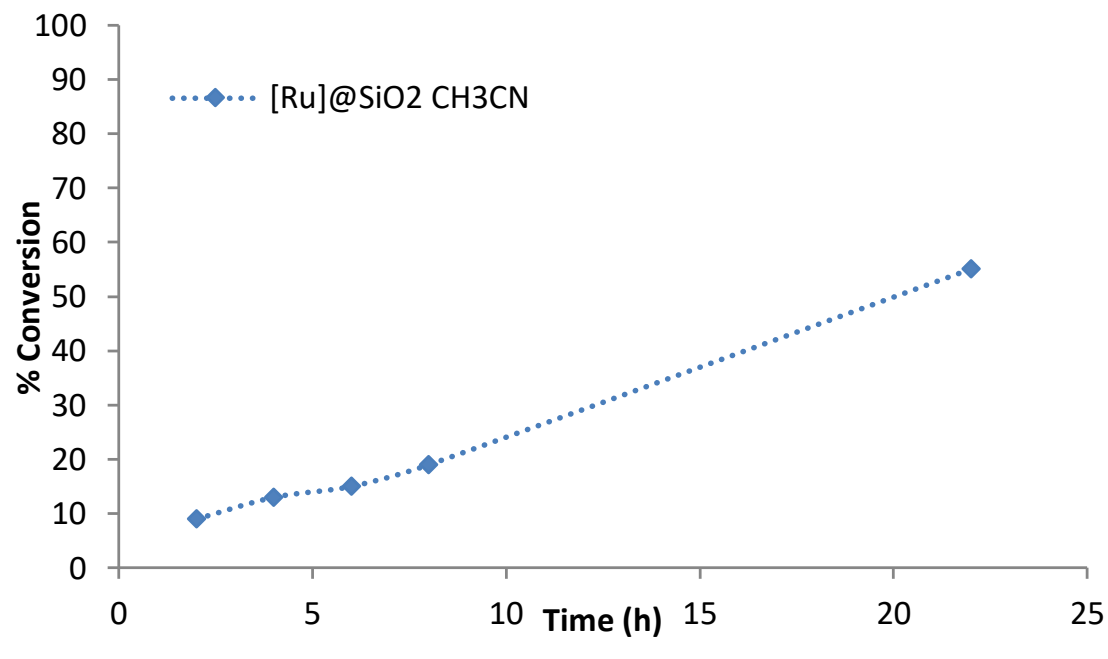




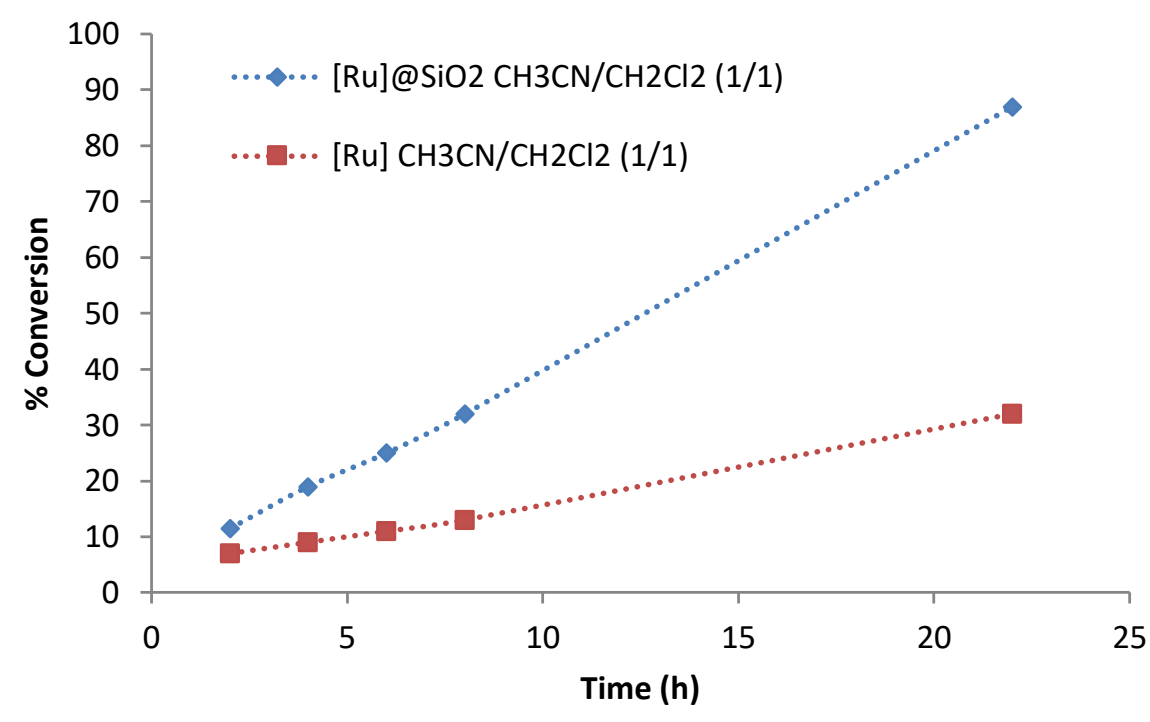

Figure S3: (a) Comparison between homogeneous and heterogeneous conditions in batch with [1,5-DHN] $=0.01$ $\mathrm{M}$ in pure acetonitrile or (b) in a mixture of acetonitrile/dichloromethane $\left(1 / 1\right.$ ratio) at $20^{\circ} \mathrm{C}$ with $0.16 \mathrm{~mol} \%$ of PC.

\section{b. Leaching measurements}

TMPyP was characterized by UV-Vis absorption and fluorescence (emission at $420 \mathrm{~nm}$ ) in acetonitrile (Fig S4). Fluorescence is 1000 times more sensitive than UV-Vis absorption therefore allowing a detection at around $10^{-9} \mathrm{M}$. In order to detect leaching, the crude reaction medium collected at the outlet of the continuous flow reaction was submitted to fluorescence analysis (Fig S5).

Several fractions were collected from the continuous flow process and analyzed by absorption and emission spectroscopy.



Figure S4: UV-Vis absorption spectrum and fluorescence spectrum (excitation at $420 \mathrm{~nm}$ ) of TMPyP. 


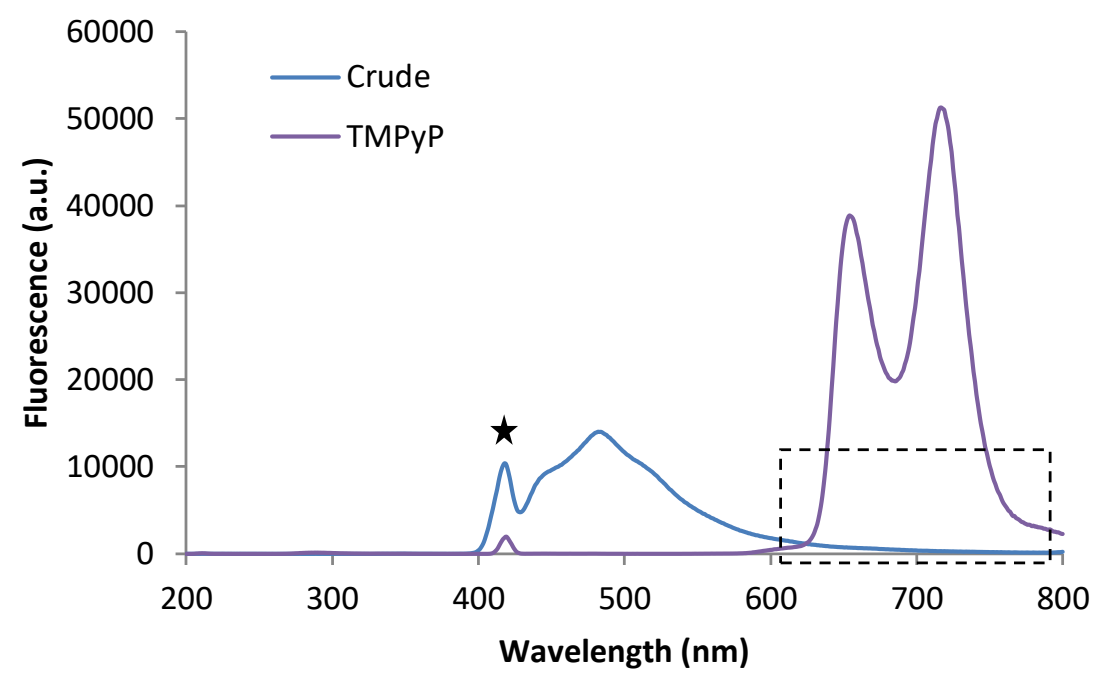

(a)

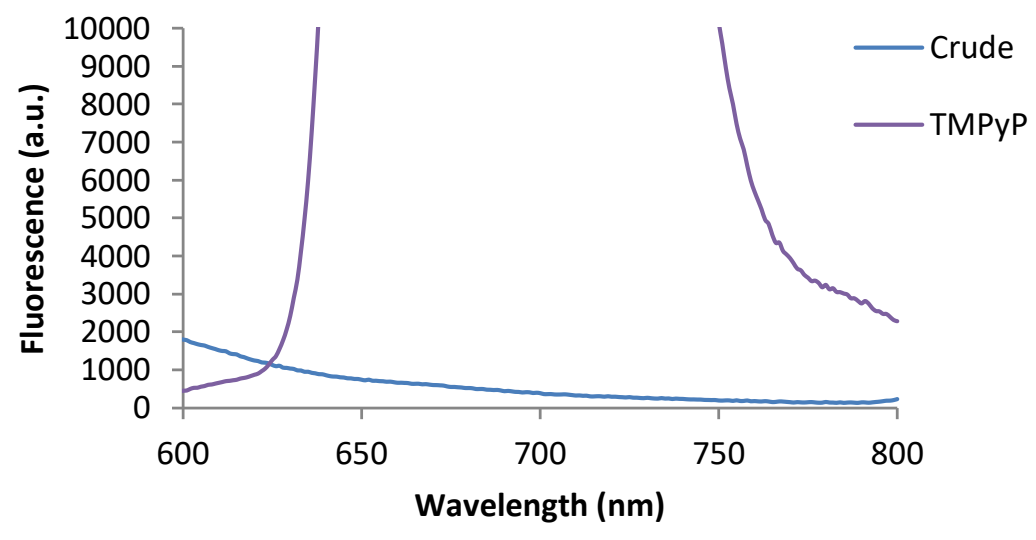

Figure S5: (a) Fluorescence spectra of the reaction crude compared to TMPyP (emission at $420 \mathrm{~nm}$ ); (b) Zoom in the $600-800 \mathrm{~nm}$ region of the fluorescence spectrum.

The comparison of the fluorescence spectra of the reaction crude reaction mixture with TMPyP clearly shows the absence of the photosensitizer within the product, meaning no leaching of the photosensitizer from silica.

\section{c. Catalyst characterizations}

Hereafter are presented the spectroscopic results concerning the Vis-absorption of the homogeneous sensitizers versus juglone at equal concentrations (Fig S6) and at concentrations mimicking catalytic conditions (Fig S7). The characterizations of solid-state TMPyP, freshly made and used TMPyP@SiO2 are also presented (Fig S8). 


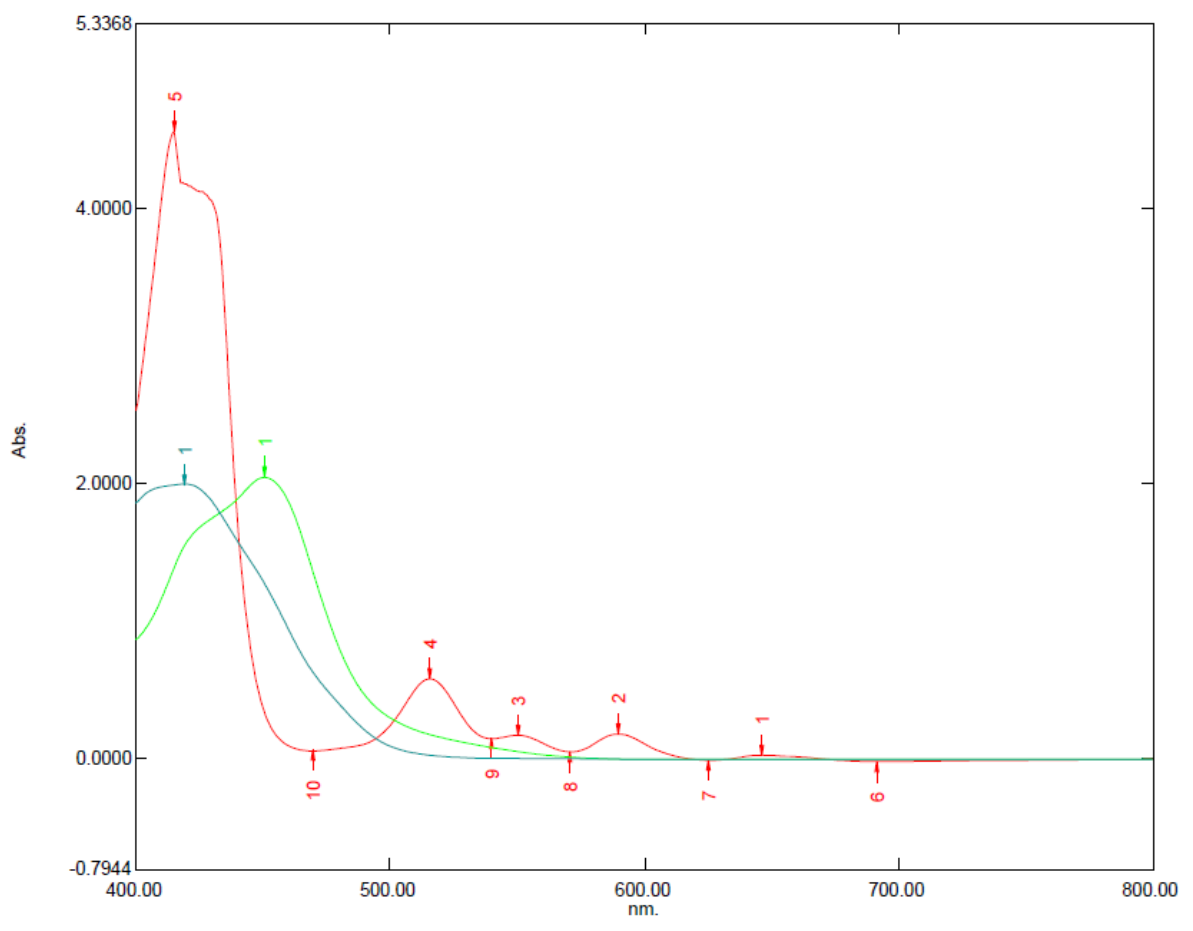

Figure S6: Absorption spectra of juglone at $0.1 \mathrm{~g}^{\mathrm{L}} \mathrm{L}^{-1}$ (blue line), TMPyP at $0.1 \mathrm{~g} \cdot \mathrm{L}^{-1}$ (red line) and $\mathrm{Ru}(\mathrm{bpy})_{3} \mathrm{Cl}_{2}$ at 0.01 g. $\mathrm{L}^{-1}$ (green line).

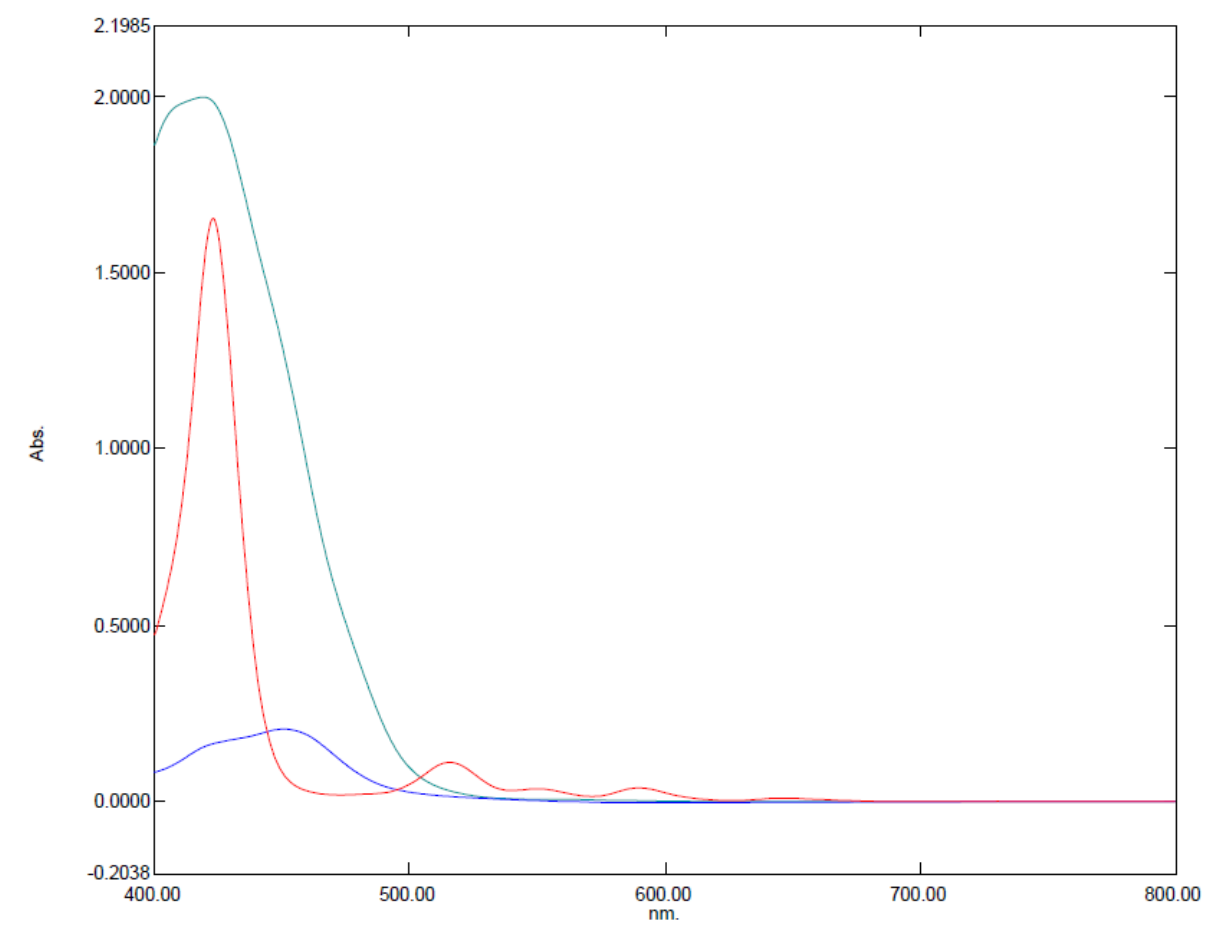


0.01 g. L $^{-1}$ (blue line). 




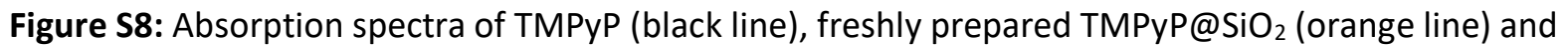
used TMPyP@SiO 2 (green line) obtained by dilution of the sample in $\mathrm{BaSO}_{4}$.

The comparison of the absorption spectra of solid TMPyP@ $\mathrm{SiO}_{2}$ with TMPyP show very similar bands. In the case of the used catalyst, a higher absorption at $420 \mathrm{~nm}$ is detected which could account for residues of juglone adsorbed on silica.

\section{d. Reaction analysis and product characterizations}

Batch and flow experiments were monitored by GC-MS and measurements were validated by ${ }^{1} \mathrm{H}$ NMR.

- Example of a GC chromatogram of a sample obtained from the flow process $\left(6.10^{-3} \mathrm{M}\right)$ with 1 cartridge containing $\mathrm{Ru}(\mathrm{bpy})_{3} @ \mathrm{SiO}_{2} 2.5 \mathrm{mg} / \mathrm{g}$ (Fig S6).



Figure S9: GCMS chromatogram of a reaction mixture, juglone $t_{R}=6.2 \mathrm{~min}$ and $1,5-D H N t_{R}=8.0 \mathrm{~min}$. 
- Example of a ${ }^{1} \mathrm{H}$ NMR analysis is presented hereafter (Fig S10):

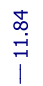

${ }^{1} \mathrm{H}$ NMR $\left(\mathrm{CD}^{3} \mathrm{CN}, 400 \mathrm{MHz}\right)$<smiles>O=C1C=CC(=O)c2c(O)cccc21</smiles><smiles>Oc1cccc2c(O)cccc12</smiles>

$91 \%$

$9 \%$

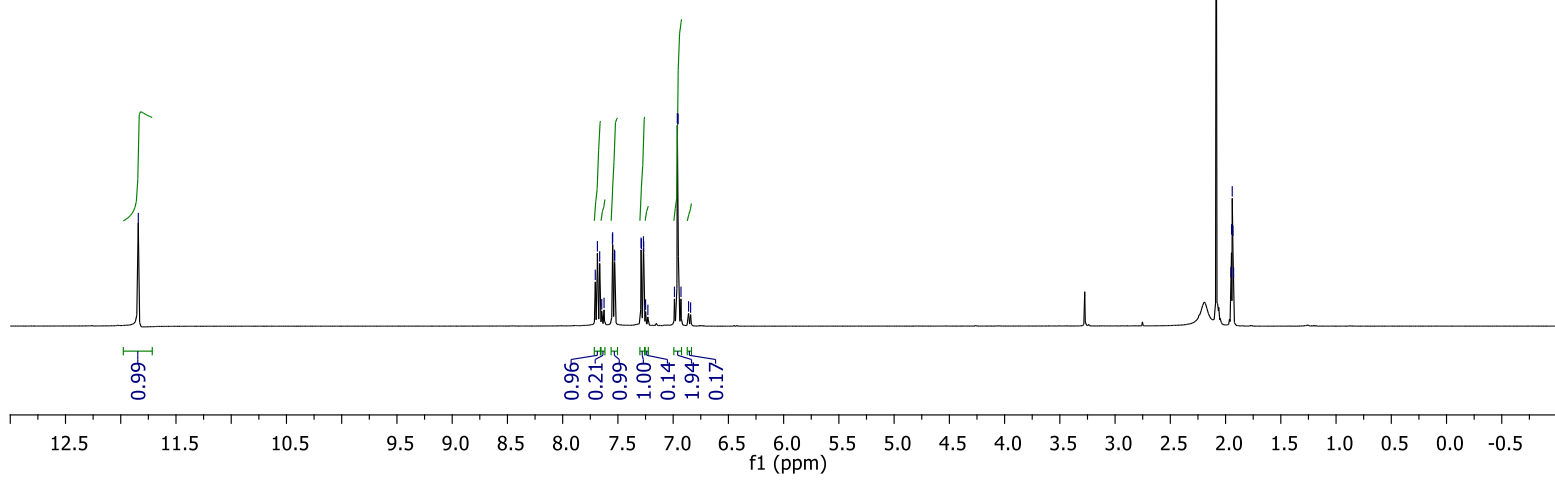

Figure S10: ${ }^{1} \mathrm{H}$ NMR analysis in $\mathrm{CD}_{3} \mathrm{CN}$ of a crude mixture after a batch reaction.

- Analysis of a crude reaction mixture $([1,5-\mathrm{DHN}]=0.006 \mathrm{M}, 0.1 \mathrm{~mL} / \mathrm{min}, 1$ cartridge filled with TMPyP@ $\mathrm{SiO}_{2} 4.5$ mg/g, no purification) (Fig S11 and S12):


${ }^{1} \mathrm{H}$ NMR $(\mathrm{CDCB}, 400 \mathrm{MHz})$



Figure S11: ${ }^{1} \mathrm{H}$ NMR analysis in $\mathrm{CDCl}_{3}$ of a crude mixture after a flow reaction at full conversion. 




Figure S12: GC chromatogram of a crude mixture after a flow reaction at full conversion. 